\title{
ПОЛОЖЕНИЕ ЖЕНЩИНЫ В СОВРЕМЕННОЙ КУЛЬТУРЕ РОССИИ И КИТАЯ
}

\section{THE POSITION OF WOMEN IN MODERN CULTURE IN RUSSIA AND CHINA}

\section{A. Vasilchenko}

Summary: The article examines the position of women in the modern culture of Russia and China from the perspective of dynamics and transformation. It is shown that in both cultures the role of women as the guardian of the family hearth gradually departs from its traditional manifestation and acquires innovative features. The uniqueness and selfsufficiency of women in modern Russian and Chinese cultures is revealed. Based on a comparative analysis, the author came to the conclusion that the current situation of women in Russia and China has more similarities than differences, it indicates the closeness of cultures and mentalities of two nations, as well as the similarity of ongoing social processes in the country.

Keywords: woman, man, family, family relations, children, divorce, society, culture, Russia, China.
Васильченко Александра Владимировна,

Кандидат культурологии, дочент, Комсомольский-на Амуре государственный университет avas_27@mail.ru

Аннотация: Исследовано положение женщины в современной культуре России и Китая в ракурсе динамики и трансформации. Показано, что в обеих культурах роль женщины как хранительницы семейного очага постепенно отходит от традиционного своего проявления и приобретает инновационные черты. Выявлена уникальность и самодостаточность женщины в современной российской и китайской культурах. На основе сравнительного анализа автор пришел к выводу о том, что современное положение женщины в России и Китае имеет больше сходств, чем различий, это указывает на близость культур и менталитетов двух народов, а также на схожесть происходящих социальных процессов в государстве.

Ключевые слова: женщина, мужчина, семья, семейные отношения, дети, развод, общество, культура, Россия, Китай.
$\mathrm{B}$ настоящее время в России и Китае особую важность приобретают проблемы, связанные с изучением национальной ментальности и самобытности, актуализируется интерес к отечественной культуре. Важность этих проблем обусловлены межкультурными взаимовлияниями и процессами глобализации. Также в настоящее время актуальность получают российско-китайские отношения, которые обуславливают межкультурные связи двух стран. В этом процессе участвуют и женщины, поэтому представляется важным проанализировать положение женщины, ее деятельность и вклад в общественно-производственную жизнь стран с разной историей и культурой.

Анализируя и сравнивая жизнь семьи и быта в российской и китайской культурах, можно отметить, что исторически основное социальное назначение женщины заключалось в ведении домашнего хозяйства и воспитания детей. Однако эта, банальная на первый взгляд, истина представляется нам важной в том плане, что семья, являясь ячейкой государства, не только воспроизводит и формирует будущих граждан, но и готовит их к общественно-производственной деятельности, и женщине здесь отводится немаловажная роль.

Цель работы: сравнить положение женщины в современной культуре России и Китая, выявить сходства и различия.
При проведении исследования использовался сравнительно-исторический метод, предоставивший возможность выявить сходства и различия в представлениях о женщине у двух разных культур, а также происходящие изменения в семейных и общественных отношениях России и Китая. Также данный метод позволил сравнить традиционное и современное положение женщины у каждой отдельной культуры. В работе применялся также психологический метод, позволивший рассмотреть особенности национальной культуры, национального характера посредством изучения особой роли и статуса женщины в семье и обществе у двух культур.

Новизна работы заключается в исследовании трансформации традиционного образа женщины, ее роли и статуса в семье и обществе в современной культуре России в сравнении с современной культурой Китая. Данное исследование осуществлялось через призму средств массовой информации, которые выступают не только трансляторами культурных норм и ценностей, но и отражают современную жизнь общества. Привлечение научных материалов позволило автору увидеть и оценить положение женщины в статике, как сложившейся многовековой системы воспитания и подготовки будущих граждан к общественной жизни государства, а использование средств массовой информации дало возможность увидеть деятельность женщины в динамике, в 
повседневной жизни семьи и общества.

В современном российском государстве изменилось традиционное представление о женщине как хранительнице семейного очага. В дореволюционной России главным ее предназначением было ведение хозяйства, рождение и воспитание детей. Все свое время и свою деятельность она должна была посвящать семье [17, с. 237]. В современной России женщина является самодостаточной личностью, наравне с мужчиной она вовлечена в различные сферы производственной и политической деятельности государства. Женщина осознает свою значимость и востребованность в общественном производстве, что находит широкое отражение в СМИ.

Влияние женщин на современную жизнь увеличивается с каждым днем. В мире уже почти не осталось тех срер деятельности, в которых женшины не могли бы проявить своего участия. Они словно спешат показать и доказать кому-то, что не хуже мужчин справятся с той или иной общественной задачей и справятся с ней гораздо лучше [14, с. 2].

Несмотря на это, семья и дети все еще являются одними из главных, приоритетных жизненных ценностей большинства современных российских женщин. Счастливая и дружная семья мыслится ими как огромное счастье, как тыл, позволяющий человеку жить полноценной жизнью, расти и развиваться детям, радоваться каждому дню [3, с. 55; 4, с. 109].

В дореволюционной культуре России женщина экономически зависела от мужчины [17, с. 237]. Для большей части современных российских семей характерна экономическая независимость жены от мужа (она также работает, зарабатывает деньги). В связи с этим, осуществляется демократизация супружеских отношений, которая происходит в разных сферах семейной жизни: переосмысливаются и подвергаются изменениям проблемы главенства семьи, ведения хозяйства и семейного бюджета, решения важных семейных вопросов. Приобретают актуальность и проблемы совместного домашнего труда, ухода за детьми и их воспитания, которые транслируются в СМИ.

Так сложилось, что в современном российском обществе работают оба супруга, поэтому домашние дела и воспитание детей приходится делить поровну: вместе делать домашние дела, а потом вместе отдыхать... Если супруги договорятся и будут вместе делать домашнюю работу, не разделяя ее на мужскую и женскую, а дети будут это видеть каждый день, они привыкнут к такому положению вещей. И если отец вместе с сыном будут привычно и беспрекословно мыть посуду после семейного обеда, ребенок никогда не будет воспринимать работу на кухне женским занятием [13, с. 29].
В современной российской культуре приобретает все большую актуальность образ эмансипированных женщин, которые стремятся получить достойное образование, сделать успешную карьеру, приобрести финансовую независимость. При этом они не спешат создавать семью.

Мне 30 лет, я не замужем, и в ближайшее время не собираюсь создавать семью. У меня два высших образования, и сейчас какраз складываются благоприятные условия для успешной карьеры. Моя мама и бабушка вышли замуж довольно рано и к 20 годам были уже мамами. Но сейчас совсем другие времена. Женшины, особенно те, кто любят свою работу, как я, не торопятся создавать семьи и обзаводиться потомством [12, с. 4].

Женская эмансипация также выражается в сознательном отказе женщины от супруга, если он не выполняет своих обязанностей в семье, не работает, не обеспечивает экономически семью, употребляет алкоголь и др.

Поколение, родившееся раньше 90-х, помнит горестное и обидное слово «безотиовщина». Наши бабушки воспитывали наших матерей: «Ребенку нужен отец! Необходимо сохранять семью любой ценой». И они сохраняли семью. Только потом понимали, что чена оказалась очень высокой. То ли дело нынешнее свободолюбивое племя. Многие современные женшины поняли, что самая бессмысленная идея на свете - это жертва во имя кого-то, особенно когда роль жертвы выпадает женшине и ребенку. Столкнувшись с мужским поведением, которое невозможно терпеть, современные женшины делают выбор в свою пользу, они сознательно отказываются от мужа и лишают ребенка отца. Времена сейчас другие, и никто не заклеймит ребенка словом «безотцовщина» [7, с. 24].

В настоящее время в российском обществе массовым явлением стали разводы, причины которых заключаются в трансформации патриархального уклада семьи, в стремлении женщин изменить свой традиционный статус домашней хозяйки и переложить свои обязанности по дому на мужа, неподготовленность женщин к семейной жизни. Данная проблема также находит отклик в СМИ.

Подруга хвалила мне своего мужа - он и еду готовит, и полы моет, и рубашки свои сам гладит, и белье стирает. Прошло некоторое время, и подруга начала жаловаться на мужа: он перестал мыть полы, потом стал требовать от жены глаженые рубашки. «Если он еще откажется готовить мне завтраки, обеды и ужины, я с ним разведусь» - жаловалась подруга на мужа, которым она привыкла повелевать, как своим рабом. В дальнейшем они действительно развелись. На развод подал муж, т.к. ему надоело быть прислугой для жены [15, с. 50]. 
В современной культуре также распространение получили нерегистрируемые сожительства (гражданские браки), сексуальные отношения молодых девушек до брака и др.[1, с. 116]. С этими проблемами связан рост так называемых «осколочных» семей с матерью и детьми, внебрачной рождаемости, происходит увеличение количества матерей-одиночек [6]. К таким явлениям уже нет отрицательного отношения со стороны современного общества, каким оно было в дореволюционной России.

Для большинства российских семей характерна малодетность, возникающая чаще всего в результате экономического кризиса в стране, бедности и нищеты [5]. И в отличие от традиционного уклада, мать и семья уже не являются единственными в воспитании и социализации индивида. В нынешней России в этом процессе активно принимают участие дошкольные учреждения, школы, вузы, неформальные объединения и др.

В связи с вышеотмеченными проблемами, которые сказываются негативно на состояние семьи, в современной России предпринимаются попытки возродить традиционное осмысление женщины как матери, хранительницы семейного очага, главной задачей которой является рождение и воспитание детей. Происходит популяризация семейных праздников, например, таких как «День семьи, любви и верности», «День Матери», «Новый год» и др. Цель этих праздников - утвердить образ традиционной, крепкой, многодетной семьи. Не работа, а семья и дети должны стать приоритетными в жизни женщины. Данная идея широко транслируется в православных СМИ.

«День семьи, любви и верности» берет свое начало из Православия. В настоящее время этот праздник призван объединить русский народ вокруг самого ченного, что есть у человека - семьи. Жизнь благоверного князя Муромского Петра и его святой супруги Февронии - это пример жертвенной и верной любви. Эта воплощенная история семейного счастья и любви волнует сердце любой женшины [9, с. 14].

Праздник «День семьи, любви и верности» проводится в русле русской православной традиции, он является отечественным историческим наследием. Во многих городах проходят торжественные мероприятия, приуроченные к этому празднику, с целью возрождения национальной культуры, создания позитивного образа семьи, особенно многодетной, закрепления этого образа в сознании российского населения. В рамках этой программы осуществляется помощь семьям в кризисных ситуациях.

Таким образом, в настоящее время относительно роли женщины в современном российском обществе складывается противоречивая картина. С одной стороны, семья и дети все еще остаются одной из важных обязанностей российских женщин. С другой стороны, роль женщины в семье и обществе, в отличие от традиционной культуры, меняется. В связи со сложившейся кризисной ситуацией в стране, женщина вынуждена участвовать в разных сферах производственной и общественной деятельности страны, экономически обеспечивать семью наравне с мужчиной.

Как и в России, в современном Китае изменилось представление о женщине, которая также мыслилась в традиционном китайском обществе как хранительница семейного очага [8, с. 307]. В середине XX в. в Китае произошли преобразования в государственной власти, повлекшие за собой и изменения в социальной сфере. Произошло установление гендерного равноправия [18]. Женщины в современном Китае обрели равные с мужчинами права и равный с ними социальный статус, получили экономическую независимость, право участия в политической жизни страны. Именно социальный прогресс постепенно разрушил традиционное восприятие женщины в Китае. В новую эпоху женщины пришли на работу и стали костяком всех слоев общества. Большое количество выдающихся женщин успешно реализуют себя в областях науки, техники, культуры, искусства и др. Они делают открытия в тех сферах деятельности, в которых доминировали мужчины. С развитием новых технологий, например, таких как Интернет и искусственный интеллект, стали появляться новые профессии, предоставляющие большие возможности для трудоустройства женщин.

Как и в России, в современном Китае все большее развитие приобретает образ эмансипированной женщины, что находит широкую трансляцию в СМИ. B $\mathrm{Hbl}$ нешнюю эпоху в сознании женщин пробуждается много новых идей, и в будущем их будет все больше и больше. Они не захотят полагаться на людей, чтобы изменить свою судьбу. Они полагаются только на себя. Они независимы и самостоятельны: это кольцо выглядит хорошо, и я могу купить его себе сама. Я также буду заботиться о себе сама [21].

Женщины хотят стать лучше, красивее, покупая себе модную одежду, высококачественную косметику, изысканные блюда, туристические путевки. Девушки стремятся получить образование, построить успешную карьеру, приобрести финансовую независимость, иметь хорошую работу. В дальнейшем, это даст возможность осуществлять более прочные отношения в семье, развивать собственный семейный бизнес. В современном Китае большое распространение получили общественные взгляды и мнения, свидетельствующие о том, что женщины, родившие детей, не должны бросать свою работу. Они обязаны строить собственную карьеру. С одной сто- 
роны, рост числа разводов и высокий уровень семейной неустойчивости заставляет женщину знать, если она не сделает свою карьеру и если вдруг брак прекратит свое существование, то такая женщина потеряет весь капитал, который приносили ей дети и семья. С другой стороны, прогресс мужчин и женщин должен идти в относительно синхронном состоянии. Женщины не должны сильно отставать от мужчин в профессиональной деятельности. Чтобы иметь хороший брак, у женщины должен быть собственный бизнес. Только становясь успешнее в профессиональной сфере, женщина может сохранить свой брак и всегда привлекать вторую половину [21].

Современные молодые люди уже не разделяют традиционных взглядов о том, что женщине, имеющей семью, следует заниматься только домашним хозяйством и детьми. Молодое поколение полагает, что сейчас эти обязанности должны выполнять оба супруга. Мужу и жене необходимо сообща решать важные семейные вопросы, иметь сходные интересы, проводить досуг вдвоем или с детьми и т.д. Таким образом, супружеские отношения в Китае теперь стали равноправными [10].

В традиционном Китае женщина-мать, имеющая много детей, пользовалась большим уважением [8]. Сейчас семьи в Китае в основном малочисленные. С одной стороны, в последние годы государство ограничивало свободу брачных отношений: одна семья - один ребенок. [20]. С другой стороны, женщины, которые потратили много сил, времени и денег на образование и карьеру, не могут уйти в декретный отпуск. Они боятся потерять профессиональную квалификацию, остаться без работы и доходов, что достаточно обосновано с их стороны: несмотря на государственные законы, защищающие интересы молодых матерей, предприятия находят различные причины для их увольнения [18]. Помимо этого, широкое привлечение женщин в сферу общественного производства значительно сокращает время, которое они могли бы уделять семье, рождению и воспитанию детей. Данная позиция находит широкий отклик в СМИ.

Беременность - это слишком тяжело, воспитание детей имеет много проблем. Овдовевшее воспитание очень сложное. Не выгодно откладывать работу из-за воспитания ребенка. Нельзя остаться в жизни без дохода. Каждый должен усердно трудиться, чтобы наслаждаться жизнью, а не быть отиом или матерью. Это своего рода mрепет жизни, рациональность выбора, осторожность по отношению к детям и ответственность за себя [23].

Также как и в России, в современном Китае, в отличие от традиционного общества, мать и семья уже не играют основной роли в воспитании и образовании детей. Эту задачу выполняют дошкольные, образовательные учреждения, включая вузы и др. [16].
За последние годы в Китае сформировались также новые принципы выбора будущей супруги. В традиционном Китае в девушках ценились следующие качества: целомудрие, скромность, послушание, уважение к родителям [11, с. 146-147]. В настоящее время считаются более предпочтительными эрудированность, предприимчивость и деловитость, а также уровень образования и доходов, состояние здоровья, возраст, внешние данные, темперамент, характер [18]. Брак для женщины уже не является обязательным, навязываемым родителями и обществом. Сегодня девушки могут создавать семьи по собственному выбору, по любви, поддерживая значимость романтических отношений. В СМИ даются разнообразные советы, касающиеся создания семьи.

Свободный выбор супруга в качестве партнера по браку должен быть вашей верой в него. Будьте сами собой, слушайте свое сердие, которое поможет выбрать того, кто, по вашему мнению, является правильным партнером по браку. Даже если в будущем что-то в вашей семье пойдет не так, вы никого не будете обвинять [24].

В современном Китае увеличивается число разводов, в больших городах до 70 \% разводов инициировано женщинами, что было недопустимо в традиционном Китае [19]. Уже не считается предосудительным для современного общества женщине быть разведенной и заключать повторные браки. Это свидетельствует о повышении социально-экономического положения женщин, их равноправия и независимости, о радикальных изменениях общественных взглядов на семью и семейные отношения. Возрастает уровень сексуальной свободы китайских женщин, некоторые из них живут в нерегистрируемых сожительствах (гражданских браках).

Однако, несмотря на все вышесказанное, в современном Китае, наблюдаются тенденции несколько изменить современное положение женщины, возродить традиционное представление о ней как хранительнице семейного очага, как матери, одной из главных задач которой является воспитание детей. Не работа, а дети, общение с ним и их воспитание могли бы стать приоритетными в жизни женщины. Эта программа отражена в СМИ, где женщина называется «матерью на полный рабочий день».

В Китае термин «мать на полный рабочий день»не так давно был непопулярным и считался содержащим отрицательные значения, такие как «некомпетентность» и «нет денег». Теперь все больще женщин добровольно выбирают стать «матерями на полный рабочий день» и гордятся ими. Некоторые эксперты прогнозируют, что, поскольку правительство Китая сейчас уже разрешает рожать двух детей, желающих женщин стать матерями полного дня будет еще больще [22]. 
Однако можно отметить, что современная женщина Китая свободна в своем выборе и может самостоятельно решать, каким видом деятельности будет заниматься.

Проанализировав современное положение женщины в России и Китае, выявляется много сходных черт.

1. Роль и статус женщины в семье и обществе в обеих странах трансформировались, по сравнению с традиционной культурой.

2. Женщины, как и мужчины, трудятся на производстве, участвуют в различных сферах общества, экономически обеспечивают семью.

3. И Россия, и Китай пришли в своей истории к относительному равноправию и демократизации мужчин и женщин в семейных отношениях и общественной жизни страны.

4. И в России, и в Китае популярен образ эмансипированной женщины.

5. В обеих странах большинство женщин уже не имеют много детей, по сравнению с тем, как это было в традиционной культуре.

6. В связи с возникшими социальными проблемами, в обеих странах осуществляются попытки возродить традиционное представление о женщине, прежде всего как матери, супруги, в центре жизни которой должна быть не профессиональная деятельность, а семья, дети, их интересы и воспитание.

С другой стороны, есть и различие: в настоящий момент в Китае действует политика, направленная на сокращение рождаемости, в России же действует противоположная политика, направленная на увеличение рождаемости. Однако, российские женщины сами не желают иметь много детей. Это связано, по нашему мнению, с социальными проблемами современного российского общества, одной из которых является экономическая нестабильность страны.

Таким образом, проведенный сравнительный анализ показал, что в современном положении женщины в России и Китае больше сходств, чем различий, что, с одной стороны, указывает на близость менталитетов и характеров этих двух, на первый взгляд непохожих стран. С другой стороны, это указывает на то, что Россия и Китай в настоящее время переживают одинаковые изменения и инновационные процессы, которые связаны с социальными, экономическими проблемами в обществе, а также с процессами глобализации. Участие женщины в современной социальной и производственно-экономической жизни государства в России и Китае все больше увеличивается. С развитием производства женщины осваивают новые профессии, занимаются бизнесом, активно участвуют в политической жизни страны, служат в армии и т.д. Женщины получили равноправие и независимость от мужчины. В политической, экономической и производственной жизни государства они могут заменить мужчину. Хотя деятельность женщины в семье уменьшается, сокращается время, которое женщина могла бы отводить семье и детям, однако ее роль в воспитании детей и хранительницы семейного очага не уменьшается и остается важной и необходимой. В связи с этим, женщина становится личностью двухсторонней, уникальной и самодостаточной, которой в силу сложившихся обстоятельств (развития производства, государственной политики и т.п.) приходится выполнять несколько социальных ролей в обществе: домашней хозяйки, матери, воспитывающей детей, - и роль труженицы, преуспевающей в какой-либо сфере общественного производства.

Результаты данной работы имеют практическую значимость и могут применяться в вузовской практике преподавания курсов по дисциплинам специальности «Культурология», а также в научно-исследовательской работе со студентами. Материалы данного исследования также могут использоваться органами социальной защиты населения при планировании работы со смешанными браками, которые уже возникли в приграничных районах России и Китая.

ЛИТЕРАТУРА

1. Антонов А. И. Судьба семьи в России XXI в. - М. :«Грааль», 2000. - 416с.

2. Бурмистрова Е. Мамы разные важны // Славянка. - Январь. - 2010. - С. 72-77.

3. Васильченко А. В. Сравнительный анализ представлений о счастье в русской и китайской культурах (статья) / Исторические, философские, политические и юридические науки, культурология и искусствоведение. Вопросы теории и практики / Тамбов: Грамота, 2017. № 8 (82). С. 54-56.

4. Воркачев С. Счастье как лингвокультурный концепт. - М.: Гнозис., 2004. - 237с.

5. В разводах виноваты измены и бедность // Российская газета : Неделя [Офиц. сайт]. № 6132 от 18 июля 2013 г. [Электронный ресурc] URL: http://www. rg.ru/gazeta/subbota/2013/07/18.html. Дата обращения: 20.03.2020 г.

6. Гаспарян Ю. А. Семья на пороге XXI в. (социологические проблемы). - СПб : Петрополис, 1999. - 320 с.

7. Гребнева, Н. Ребенка без отца оставила! / Н. Гребнева // Будуар. - № 9 (199). - Сентябрь. - 2017. - С. 24-25.

8. Кравцова М. Е. История культуры Китая. - М. : Издательство «Лань», 2003. - 416с.

9. Кравченко И. Семья - это основа жизни // Славянка. - Июль. - 2008. - С. 14-16. 
10. Кузьменко Е. Б. Особенности взаимоотношений в китайской семье // Молодой ученый. - 2015. - № 19. - С. 99-102. URL https://moluch.ru/ archive/99/22345/. Дата обращения: 22.03.2020 г.

11. Малявин В. В. Китайская цивилизация. - М. : ИПЦ «Дизайн. Информация. Картография»: АСТ, 2003. - 627 с.

12. Наедине с психологом // Веста. - № 8 (267). - Август. - 2017. - С. 4-5.

13. Наедине с психологом // Веста. - № 11 (282). - Ноябрь. - 2018. - С. $28-29$.

14. Николаев С. Слово пастыря // Славянка. - Июль. - 2006. - С. 2-3.

15. Ошибки, о которых мы будем сожалеть // Веста. - № 7 (266). - Июль. - 2017. - С. 50-51.

16. Пащенко Г. Отношение родителей и детей в Китае / Г. Пащенко, Инь Фен, Оу Сян // Электронный архив Сиамского государственного университета. [Электронный ресурс] URL: http:// essuir.sumdu.edu.ua/bitstream/123456789/18062/1/15.pdf. Дата обращения: 26.03.2020 г.

17. Платонов 0. А. Русская цивилизация. История и идеология русского народа. - М. : Алгоритм, 2010. - 944 с.

18. Почагина 0. Семья: новые формы - иные ценности. [Электронный ресурс] http://www.strana-0z.ru/2008/3/semya-novye-formy-inye-cennosti.-3aгл. c экрана. Дата обращения: 26.03 .2020 г.

19. Хайжуй Ли Китай. Знакомство с древней культурой. - М. : Вече, 2004. - 208 с.

20. Юлиан Лин Китайская семья и культура [Электронный ресурс] http://www.oppi.uef.fi/aducate/projektit/monikko/translations/rus/Kiinalainen-perhe-jatapakulttuuri-rus.pdf. Дата обращения: 20.03.2020 г.

21. 来源:搜狐《2019中国职业女性图鉴：职业天花板创业女性与“她经济 2019-05-13 (Иллюстрация китайских женщин-профессионалов в 2019 году: женщины, достигшие высот в бизнесе).

22. 来源：新华社 《二孩政策让中国更多职业女性回归家庭》责任编辑: 王萌萌). 2016年02月24 (Политика в отношении двух детей, направленная на возвращение профессиональных женщин в семью в Китае).

23. 来源 知乎 作者 周冲 «为什么现在的90后越来越不想生孩子了 2018-08-07. (Почему сейчас, после 90-х годов, все больше и больше не хотят иметь детей?)

24. 来源 百度 «自由恋爱的好处 2018-03-01 (Преимущества свободной любви).

(с) Васильченко Александра Владимировна (avas_27@mail.ru)

Журнал «Современная наука: актуальные проблемы теории и практики»

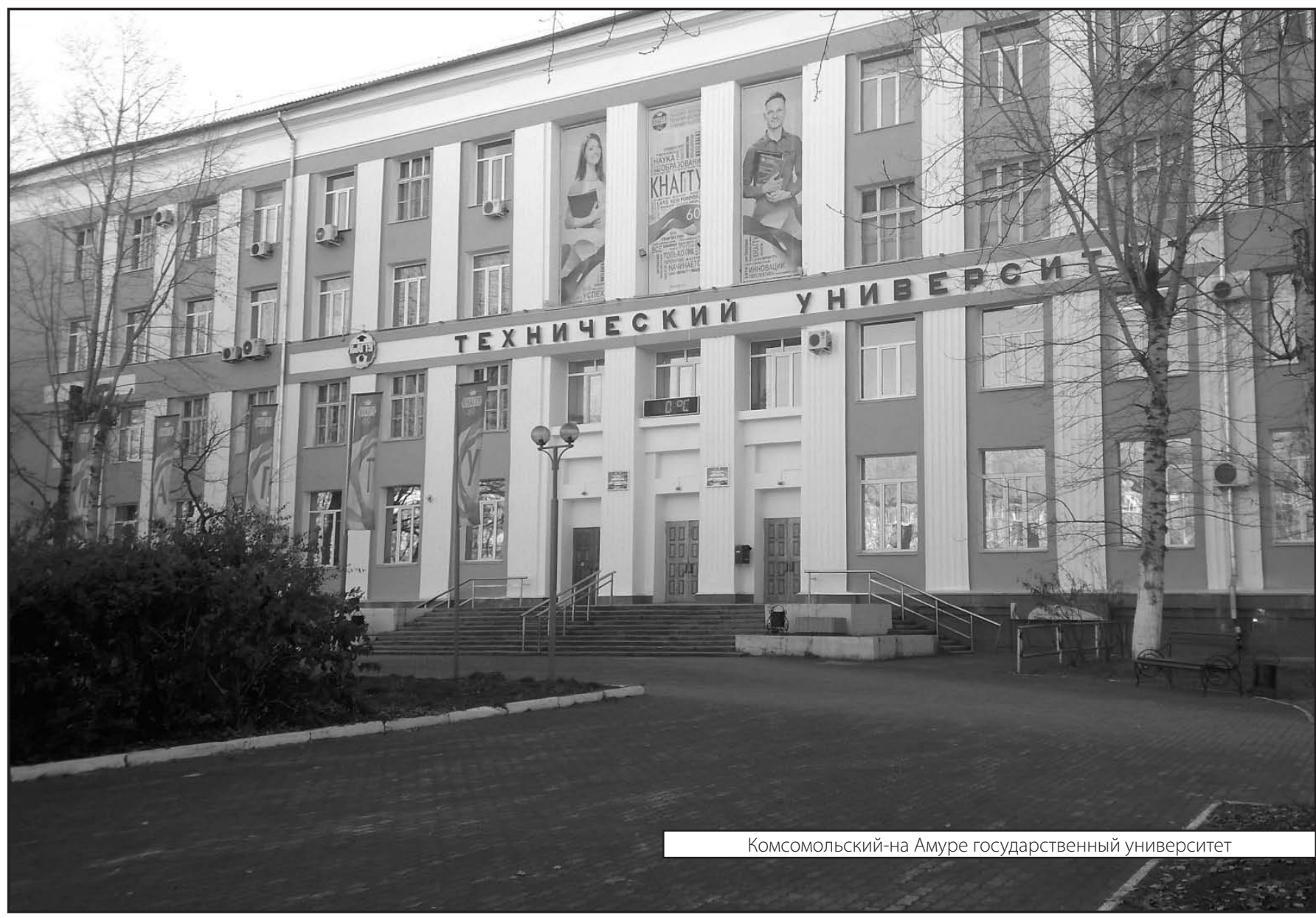

